\title{
Konseptualisasi dalam Gastro Diplomasi: Sebuah Diskusi Kontemporer dalam Hubungan Internasional
}

\author{
Riski M Baskoro ${ }^{1}$
}

\begin{abstract}
Food has a story and people are the sole object constructing the story. Food also has meaning for a community group, where tradition, customs, values, and geographical location will determine what kind of dish is placed in a serving device. In other words, food can not be separated from the cultural aspects of a community group, because of course every community or a nation has a distinctive style to the food and in the end can set the identity. The concept of gastronomy is certainly not a rare and peculiar thing, but when it is combined with diplomacy, the story may be different. A decade and a half ago, a leading weekly magazine raised the news about gastro diplomacy activities and made International Relations scholars captivated to further interpret this concept. This paper will elaborate the concepts, practices, and debates surrounding gastro diplomacy regarding disparities to similar concepts. In addition, this paper also tries to analyze the affiliation of gastro diplomacy with nation branding. The purpose of this paper is to provide a comprehensive overview of the concept of gastro diplomacy.
\end{abstract}

Keywords: gastro diplomacy, cultural diplomacy, public diplomacy, nation branding

\begin{abstract}
Abstrak
Makanan memiliki sebuah kisah dan manusia merupakan objek tunggal yang mengkonstruksi kisah itu. Makanan juga memiliki makna bagi suatu kelompok masyarakat, dimana tradisi, adat istiadat, nilai-nilai sampai letak geografis akan menentukan hidangan jenis apa yang diletakan dalam sebuah peranti saji. Dengan kata lain, makanan tidak bisa terlepas dari aspek budaya suatu kelompok masyarakat, karena tentunya setiap kelompok masyarakat ataupun suatu bangsa memiliki corak yang khas terhadap makanannya dan pada akhirnya dapat menata identitas. Konsep tentang gastronomi sudah tentu bukan hal langka dan ganjil, namun ketika ini dipadukan dengan diplomasi, ceritanya bisa lain. Satu setengah dekade lalu, sebuah majalah mingguan terkemuka mengangkat berita tentang aktivitas gastro diplomasi dan membuat para akademisi Hubungan Internasional terpikat untuk menginterpretasi lebih jauh konsep ini. Tulisan ini akan mengelaborasi konsep, praktik, dan perdebatan seputar gastro diplomasi mengenai disparitas terhadap konsep-konsep yang serupa. Selain itu, tulisan ini juga mencoba menganalisis afiliasi gastro diplomasi dengan nation branding. Tujuan dari tulisan ini untuk memberikan gambaran secara menyeluruh mengenai konsep gastro diplomasi.
\end{abstract}

Kata-kata Kunci: Gastro Diplomasi, Diplomasi Kebudayaan, Diplomasi Publik, Nation Branding

\section{Pendahuluan}

Pada tahun 2002, majalah mingguan

The Economist Asia mengangkat berita tentang skema kebijakan politik Thailand yang tersistematis untuk menstimulasi program ambisius pemerintahan Negeri Gajah Putih yang bertajuk Global Thai, dimana pemerintah mengharapkan adanya eskalasi restoran dengan cita rasa Thai di Amerika Serikat (Economist, 2002). Pemerintah Thailand mengklaim bahwa masyarakat internasional tidak canggung terhadap cita rasa mereka. Hal ini diyakini karena kejayaan program Global Thai yang bertransformasi menjadi Thai Cuisine to the World, yakni peningkatan kuantitas restoran di seluruh negara agar

\footnotetext{
${ }^{1}$ Staf Pengajar pada Jurusan Hubungan Internasional, President University. Email: riskibaskoro@ president.ac.id
} 
makanan otentik Thailand dapat dilegitimasi oleh masyarakat internasional (ThaiFoodtotheWorld, 2005).

Pada tatanan ini, nampaknya konsep gastro diplomasi kian populer di permulaan abad milenial. Selebrasi terhadap konsep gastro diplomasi dapat terlihat ketika banyak negara lain turut menggunakan kebijakan politiknya untuk mempromosikan jamuan makanan khasnya. Saya mengira konsep gastro diplomasi menjadi prominen karena perana pemerintah Thailand yang selanjutnya diberitakan oleh majalah The Economist (2002). Dengan kata lain, kontribusi majalah asal Inggris tersebut cukup signifikan untuk mempopulerkan konsep gastro diplomasi. Di awal abad milenial, banyak negara tidak hanya mempromosikan sejarah, seni maupun keindahan alam untuk urusan wisata, tetapi juga banyak negara mempromosikan kuliner sebagai brand image (Tettner \& Kalyoncu, 2016). Namun demikian, banyak orang yang masih belum memahami konsep ini secara holistik. Seperti apa yang telah saya kemukakan pada fragmen abstraksi, jika berwacana tentang gastronomi, atau yang dalam bahasa Indonesia disebut upaboga (Ketaren, 2016), mungkin sudah banyak ahlinya. Tetapi jika gastronomi diasosiasikan dengan praktik diplomasi, maka jalan ceritanya bisa jadi berbeda.

\section{Gastro Diplomasi: Produk Usang dalam} Kemasan Baru?

Bagi saya, tidak ada tulisan yang lebih komprehensif dalam mengupas gastro diplomasi sebagai kerangka konseptual selain tulisan Rockower (2012). Kreasinya sangat signifikan dan masif dalam mengeksplanasi gastro diplomasi berikut aktivitas-aktivitas serupa. Tentu saja tulisannya banyak diapresiasi dan juga dijadikan sebagai rujukan oleh berbagai ilmuwan hubungan internasional. Hal ini dapat terjadi karena Rockower (2012) menawarkan elaborasi yang konkret tentang konsep gastro diplomasi.

Secara sederhana, gastro diplomasi adalah "the act of winning hearts and minds through stomachs" (Rockower, 2012).Melalui pendekatan dialogis, suatu negara menawarkan pesona kulinernya kepada audiensi lain, agar mereka familiar terhadap cita rasa suatu negara. Gastro diplomasi juga menawarkan akses pragmatis bagi mereka yang tidak memiliki kesempatan untuk rekreasi, sehingga mereka tetap memiliki peluang untuk mempelajari kebudayaan lain melalui sense of taste. Di dalam tulisan yang berbeda dengan Rockower (2012), Pham (2013) mengklaim bahwa gastro diplomasi adalah usaha praktik pemerintah dalam mengekspor warisan kuliner nasional sebagai bagian daripada diplomasi publik untuk meningkatkan national brand awareness, investasi ekonomi dan 
perdagangan. Dalam narasi ini, jika Rockower (2012) menawarkan sesuatu yang lebih praktis tetapi abstrak, maka Pham (2013) menjelaskan lebih detail dengan melihat negara sebagai aktor sentral.

Kendati demikian, Pham (2012) nampaknya mengalpakan aktor lain yang malahan membutuhkan absennya pemerintah, seperti chef, artis, agen wisata, perusahaan hubungan publik, media sosial, dan praktisi diplomasi publik (Zhang, 2015). Jika pemerintah dijadikan aktor tunggal maupun sentral dalam kegiatan gastro diplomasi, hasilnya bisa saja program-program tersebut tidak mendapatkan validasi oleh audiensnya. Hal ini disebabkan kegiatan tersebut diyakini oleh audiens sebagai kegiatan propaganda, yang tidak lepas dari narasi politik untuk memuluskan kepentingan nasional (Mark, 2003). Senada dengan Mark (2003), argumen lain mengungkap bahwa sejatinya diplomasi modern perlu mereduksi dominasi aktor negara untuk menghilangkan propaganda yang berkonotasi negatif selama Perang Dunia dan Perang Dingin (Buckle, 2012). Dengan kata lain, masyarakat luar negeri sudah memiliki stigma terhadap program yang langsung dikelola oleh pemerintah. Sebabnya, pendekatan gastro diplomasi selalu berada pada dimensi soft power yang memerlukan eksistensi multi-aktor dalam mewujudkan aktivitas politiknya (Purwasito, 2016).
Di Indonesia sendiri, gastro diplomasi sudah mulai dibicarakan dikalangan akademisi, salah satunya adalah hasil penelitian yang diketuai oleh Purwasito (2016). Dalam laporan tersebut, definisi yang dikemukakan adalah:
"suatu kegiatan dan aktivitas terorganisir dari warga negara di luar negeri, yang bersangkut paut dengan kuliner atau gastronomi dan berbagai turunannya. Dengan begitu Gastro diplomasi bukan saja sekedar berbicara makanan di meja makan namun berhubungan erat dengan kebijakan ekonomi suatu bangsa dan secara langsung berkaitan dengan kebijakan politik suatu negara, khususnya kebijakan dalam bidang diplomasi ekonomi dan diplomasi budaya guna mencapai tujuan negara dalam mencapai kepentingan nasional."

Purwasito (2016) meyakini bahwa kegiatan ini dilakukan oleh warga negara di luar negeri, yang merujuk kepada diaspora atau pegawai kedutaan. ataupun anggota keluarga kedutaan, atau bisa saja pelaku nonpemerintah yang memiliki tujuan organsisi mempopulerkan makanan Indonesia di luar negeri, seperti Indonesia Gastronomy Association (IGA).

Gastro diplomasi sebenarnya merupakan terminologi yang baru di abad 21, sedangkan gastronomi sendiri adalah konsep yang sudah sangat lama digunakan (Nirwandy \& Awang, 2014).Utilitas konsep gastronomi bisa dilacak dengan pendekatan historis, 
semenjak 12.000 tahun lalu (Spence, 2016).

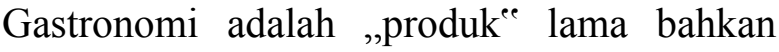
dapat ditemui puluhan ribu tahun lalu. Hanya saja, jika menggunakan terminologi gastro diplomasi, maka „kemasannya ${ }^{\text {ee }}$ menjadi lebih aktual. Menurut Ketaren (2016), gastronomi atau upaboga adalah seni memakan (the art of good eating), yang mana tidak hanya rasa yang diutamakan dalam sebuah piranti saji, namun juga kajian historis, makna, simbol maupun status menjadi hal yang diperhatikan. Sementara itu, kuliner atau boga adalah seni memasak (the art of good cooking). Ketika makanan dijadikan komoditas diplomasi, maka sebutannya adalah gastro diplomasi. Hal inilah yang menyulitkan banyak orang untuk dapat memahami kajian gastro diplomasi, geneologi terminologinya yang tidak serupa. Kendati demikian, hal yang perlu diingat adalah, ketika gastronomi memasuki ranah diplomasi maka kajiannya bukan lagi berkutat pada masalah filosofis makanan semata, melainkan suatu praktik atau usaha suatu negara dan non-negara untuk menceritakan kisahnya tentang makanan lokal yang mereka miliki.

Dalam kajian hubungan internasional, kita mengenal adanya dua pendekatan, yakni soft power dan hard power (Nye, 2004). Gastro diplomasi berada pada ranah soft power, yang mana kuliner dapat diartikan sebagai pendekatan tanpa menggunakan ancaman dalam berinteraksi dengan masyarakat luar negeri, yang dapat membuka akses terhadap kemungkinan kerjasama ekonomi maupun politik antarnegara (Wilson, 2013). Tentunya gastro diplomasi tidak menggunakan instrumen militer dalam berinteraksi dengan bangsa lain sesuai dengan perspektif soft power, melainkan makanan tradisional atau lokal yang dijadikan sebagai instrumen „perangnya ${ }^{e e}$. Rockower (2012) berasumsi bahwa gastro diplomasi tidak berupaya untuk win the hearts and minds through rational information, melainkan lebih merujuk kepada hubungan afeksi, yang mana makanan adalah media sentral dalam berkomunikasi antarbangsa.

Makanan merupakan objek transenden dalam aktivitas gastro diplomasi. Namun, tidak semua kegiatan yang menggunakan makanan atau kuliner sebagai alat komunikasi maupun diplomasi bisa dieksplanasi oleh konsep ini. Misalnya, promosi produk-produk makanan yang dimiliki oleh perusahaan privat, pelaku bisnis kuliner, atau perusahaan produk makanan instan, dan kemudian mereka menyelenggarakan festival kuliner di luar negeri. Itu artinya tidak serta merta perilaku ini dapat dilibatkan kedalam wacana gastro diplomasi (Rockower, 2012). Gastro diplomasi cenderung membutuhkan kebijakan strategis yang disponsori oleh pemerintah, walaupun pada akhirnya pemerintah perlu 
memberikan akses lebih terhadap segala bentuk kegiatannya kepada aktor nonpemerintah. Hal itu sejalan dengan Mark (2003) yang beranggapan bahwa kesuksesan program-program diplomasi yang menargetkan kepada people to people contact perlu mengebiri dominasi pemerintah dan memberikan kesempatan lebih pada aktor non -pemerintah, agar masyarakat luar negeri percaya programnya tidak berafiliasi dengan propaganda.

Aktor-aktor non-pemerintah yang umumnya berperan dalam gastro diplomasi adalah chef celebrity, perusahaan makanan, agen tourism, public relations firms, praktisi diplomasi publik, program masak di televisi, dan melibatkan media sosial (Zhang, 2015). Menurut penulis, Lembaga Swadaya Masyarakat (NGO) juga turut berkontribusi dalam praktiknya, selain masyarakat diaspora sebagai garda terdepan dalam mempromosikan kuliner nasional, mengingat peranan kedutaan atau kantor resmi pemerintah (aktor negara) di luar negeri hanya dilibatkan pada urusan resmi hubungan antarnegara. Namun, ketika merujuk kepada people to people contact, peranan institusi non-negara sepatutnya lebih dominan. Pada akhirnya, gastro diplomasi memiliki potensi yang substansial sebagai alternatif pemerintah untuk berinteraksi dengan masyarakat luar negeri melalui instrumen kuliner yang notabene dapat melampaui batas negara dan mengonstruksi cross-cultural understanding dengan harapan mewujudkan kooperasi konkret antar bangsa (Chapple-Sokol, 2013, hal. 161-183).

Potensi yang ada pada gastro diplomasi, seperti yang sudah dikemukakan di awal, adalah membuka akses kerjasama ekonomi dan politik. Potensi ini bermula ketika makanan atau kuliner direkognisi sebagai identitas sebuah bangsa, wadah pemersatu bangsa, ataupun sebagai sebuah status yang merujuk pada konsep nasionalisme (Wilson, 2013). Selanjutnya, Wilson (2013) berargumen karena adanya identitas kolektif dan semangat nasionalisme, suatu kelompok tersebut berkehendak untuk memprominenkan identitas mereka, dan instrumen sederhana dalam memperkenalkan identitas suatu kelompok masyarakat atau suatu bangsa secara universal adalah melalui kuliner. Sehingga, hanya dengan mempromosikan makanan khas suatu bangsa dapat memberikan gambaran tentang etnografi masyarakat tersebut. Hal itu pada akhirnya dapat mengukuhkan kolaborasi, khususnya di bidang ekonomi, politik maupun kebudayaan. Dengan kata lain, makanan bukan hanya sebatas bagaimana manusia mempertahankan hidup. Makanan memiliki cerita, dan cerita tersebut dapat dikemas dan dijual kepada masyarakat lain melalui bingkai 
gastro diplomasi.

\section{Interelasi Gastro Diplomasi, Diplomasi}

\section{Kebudayaan dan Diplomasi Publik}

Ada konsensus di antara para ahli bahwa gastro diplomasi merupakan substansi dari diplomasi publik. Rockower (2012), Pham (2012), Nirwandy dan Awang (2014) memiliki pemahaman yang sama bahwa dimensi gastro diplomasi berada pada kajian diplomasi publik. Namun, sebelum menentukan berada di wilayah mana gastro diplomasi ini, tentu perlu diperhatikan pengertian dari diplomasi publik itu sendiri. Diplomasi publik adalah usaha, aktivitas, kegiatan aktor negara, maupun yang berasosiasi dengan aktor negara dan aktor nonnegara untuk memahami kultur, sikap dan tingkah laku dalam membangun dan menata hubungan serta mempengaruhi opini dan aksi dengan maksud meningkatkan kepentingan dan prestis mereka (Gregory, 2008).

Kendati demikian, Buckle (2012) berpendapat, tidak ada kesepakatan yang pasti dari para akademisi terkait deskripsi tentang diplomasi publik, misalnya, jika berdiskusi mengenai si pelaku diplomasi publik. Dalam riwayatnya, diplomasi publik pertama kali diperkenalkan oleh Edmund Gullion yang pada saat itu menjabat sebagai dekan di Fletcher School of Law and Diplomacy, Tufts University di tahun 1965 (Cull, 2006).
Awalnya, diplomasi publik disponsori dan dilakukan langsung oleh aktor negara, namun pasca-Perang Dingin, dan terutama pasca-9/11 (Leonard, 2002), aktor pelaku diplomasi publik bergeser dan lebih banyak melibatkan aktor non-negara karena impresi dari perkembangan teknologi (Buckle, 2012).

Ada tiga hal yang perlu diperhatikan dalam diplomasi publik, yaitu: (1) aktor yang berperan tidak hanya negara tapi juga nonnegara, walaupun pada masa kebangkitan diplomasi publik pada masa Perang Dingin, aktor sentralnya adalah negara; (2) target dari diplomasi publik adalah masyarakat mancanegara; (3) diplomasi publik menggantungkan pada sisi positif suatu negara atau bangsa dalam melakukan interaksi dengan publik mancanegara (Mellisen, 2005). Bagi diplomasi publik, sangat lah penting untuk memberikan informasi terkini tentang hal-hal yang baik bagi suatu negara. Hal ini sejalan dengan tujuan diplomasi publik yang menekankan bahwa publik mancanegara perlu mengetahui tentang negara atau bangsa tertentu agar mereka memahami, mengetahui, dan mempelajari sehingga mereka mengapresiasi dan pada akhirnya berujung kepada dukungan kepentingan nasional negara yang melakukan diplomasi publik (Leonard, 2002).

Pada awalnya, aktivitas diplomasi publik dipelopori oleh Amerika Serikat saat 
Perang Dingin, dengan misi utama membendung paham komunisme di Amerika Latin, Eropa maupun Asia dengan dibentuknya United States Information Agency (USIA) sebagai institusi di bawah supervisi pemerintah Amerika Serikat pada saat itu. USIA memiliki motif untuk menyebarkan paham dan nilainilai yang diklaim oleh Amerika Serikat sebagai jembatan menuju kedamaian abadi, yakni; paham demokrasi, toleransi, the rule of law dan pluralisme (Buckle, 2012).

Buckle (2012), mengklaim bahwa tidak ada negara yang memiliki pengaruh besar di abad ke-20 kecuali Amerika Serikat, dan hal ini disebabkan oleh kapasitas USIA yang mampu berkomunikasi dengan baik dengan masyarakat mancanegara. Jika Amerika Serikat melalui USIA mampu untuk memberikan image yang positif terhadap audiens, maka audiens akan memahami kultur Amerika. Ketika mereka memahami kultur tersebut, perang terbuka antara negara demokratis bisa terhindakan atau bahkan tidak pernah terjadi. Inilah yang sebenarnya diinginkan oleh Amerika Serikat. Jika seluruh negara memiliki paham liberalisme, hasilnya adalah kedamaian abadi dalam hubungan interaksi antarnegara, sesuai dengan cita-cita Woodrow Wilson sebagai bapak liberalisme di Amerika (Thies \& Pecquet, 2010).

Kendati demikian, diplomasi publik mengalami degradasi terbesarnya pasca-Perang
Dingin di Amerika Serikat, dengan dibebastugaskannya USIA sebagai ujung tombak diplomasi publik negara (Schneider, 2006: 191-203). Padahal Amerika Serikat masih memerlukan lembaga seperti USIA, untuk memenangkan hati dan pikiran melalui jalur kebudayaan dalam mendistorsi gerakan anti-Amerika, negara totalitarian, maupun kaum ekstrimis (Finn, 2003: 15-20).

Secara kajian historis, objektif, aktor dan target audiens, diplomasi publik memiliki keterkaitan yang sangat erat dengan diplomasi kebudayaan. Pertanyaannya adalah; dimana letak perbedaan antara kedua terminologi ini? Sebelum membahas lebih lanjut tentang relasi keduanya, penulis mengutip definisi diplomasi kebudayaan. Diplomasi kebudayaan adalah "suatu pertukaran ide atau gagasan, informasi, kesenian dan seluruh aspek yang melibatkan kebudayaan lainnya di antara bangsa-bangsa dan masyarakat dalam usahanya mendorong saling pengertian" (Cummings, 2003). 


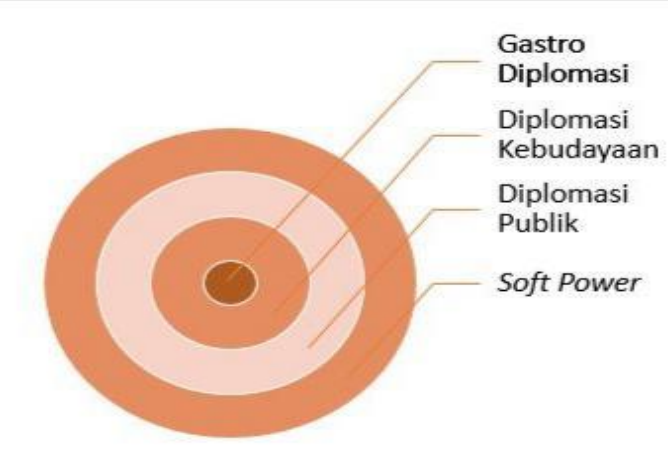

Diagram 1. Interelasi antar Konsep

Secara sederhana, interkoneksi antara konsep-konsep yang terlibat dalam kajian gastro diplomasi dapat dilihat pada diagram di atas ini. Penjelasannya adalah; pertama, tidak bisa dipungkiri bahwa gastro diplomasi adalah bagian dari diplomasi kebudayaan, karena gastronomi atau seni dalam makanan merupakan produk budaya suatu masyarakat (Ketaren, 2016). Kedua, diplomasi kebudayaan merupakan sub dari diplomasi publik, jika merefleksikan dari sudut pandang historis perkembangan diplomasi kebudayaan dan diplomasi publik pasca-Perang Dunia. Pada kajian diplomasi publik, komunikasi secara kontinu dan jangka panjang menjadi fundamental karena bertautan dengan pemunculan untuk saling memahami satu sama lainnya (Leonard, 2002).Begitu pula dengan

diplomasi kebudayaan, yakni untuk memenangkan hati dan pikiran melalui unsur kebudayaan. Ketiga, dari seluruh konsepkonsep yang ada, semuanya merujuk kepada soft power, yang mana menurut Nye (2004) instrumen kebudayaan adalah sumber prioritas. Terakhir, menurut penuis semua konsep saling terkait, walaupun masih terjadi silang pendapat di antara para ahli mengenai konsep-konsep ini, yang menyebutkan mereka semua memiliki fungsinya masing-masing dan tidak bisa digeneralisasikan menjadi satu unit yang utuh seperti apa yang telah digambarkan dan dijelaskan pada diagram 1 .

\section{Gastro Diplomasi, Serupa Tapi tak Sama}

Rockower (2012) menjelaskan dengan sangat terperinci tentang konsep gastro diplomasi dengan konsep lain yang hampir bisa disebut mirip atau bahkan sama. Rockower secara tegas mendikotomi gastro diplomasi, kuliner diplomasi, dan diplomasi

makanan. Berbeda dengan pemikiran Rockower (2012), Chapple-Sokol (2013) menganggap semua konsep tersebut adalah sama. Chapple-Sokol mengklaim bahwa semua hal yang berhubungan dengan boga yang menjadi wacana dalam studi hubungan internasional disebut diplomasi kuliner, walaupun dia mencoba membagi kedalam dua ranah, yakni diplomasi kuliner privat dan diplomasi kuliner publik untuk target audiensinya. Akan tetapi, Rockower (2012) nampaknya berbeda sudut pandang dalam hal tersebut, karena dia lebih meyakini konsepkonsep diplomasi yang berkaitan dengan boga 
memiliki disparitas jika dianalisis dari ruang fungsionalisme.

Dalam tulisannya, Rockower (2012) menyatakan adanya polaritas dalam konsepkonsep yang bersinggungan dengan gastro diplomasi. Misalnya diplomasi kuliner (culinary diplomacy) yang merupakan sebuah usaha memperkuat hubungan bilateral melalui jamuan makan yang melibatkan pejabat negara lain. Karakteristik diplomasi kuliner adalah menggunakan jamuan makan bersama untuk kepentingan diplomatik semata, ditengahtengah negosiasi formal antarnegara dengan maksud mempengaruhi hasil negosiasi. Contohnya adalah ketika Presiden Republik Korea Moon Jae-In menjamu Presiden Amerika Serikat Donald Trumph dalam perjamuan makan malam mewah (lavish banquet) di tengah-tengah krisis di Semenanjung Korea demi mengamankan Semenanjung Korea dari provokasi Kim JongUn (Martosko, 2017). Winston Churchil, perdana menteri Inggris era Perang Dunia II, menyebutnya dengan istilah table-top diplomacy (Pham, 2013), yang kurang lebih memiliki interpretasi yang sama dengan diplomasi kuliner ala Rockower (2012: 1-12).

Singkatnya, diplomasi kuliner lebih cenderung kepada jamuan makan formal dan mewah yang melibatkan hanya para pejabat negara saja. Sementara, gastro diplomasi tidak berada pada level elit, melainkan target audiensinya adalah publik atau di akar rumput (grass roots). Sedikit berbeda terminologi ketika menggunakan perspektif Chapple-Sokol (2013), dengan sasaran kaum elit birokrasi disebut dengan diplomasi kuliner privat yang menitikberatkan pada diplomasi "di balik pintu". Namun jika sasarannya kaum "akar rumput", Chapple-Sokol menyebutnya sebagai diplomasi kuliner publik.

Hal yang menarik untuk dikaji secara natural adalah adanya hubungan yang ketat antara proses pengambilan keputusan (decision making) seorang atau sekelompok pejabat pemerintah dengan diplomasi kuliner. Dalam jamuan makan bersama, secara biologis, manusia akan melepaskan zat endorpin, dan zat ini rupanya memiliki peranan yang sangat vital untuk urusan kesenangan, kebahagiaan, ataupun ikatan sosial. Seringkali, dalam urusan birokrasi, komunikasi dan negosiasi jamuan makan menjadi salah satu faktor yang dominan dalam mempengaruhi proses pengambilan keputusan yang ditentukan oleh kaum birokrat. Pada dasarnya, proses pengambilan keputusan itu tidak rasional, karena dalam ruang diplomasi kuliner, perjamuan makan yang mungkin menentukan arah pengambilan keputusan tersebut. Dengan kata lain, dalam perjamuan makan, hubungan afeksi lebih eksplisit karena mempengaruhi zat endorpin 
manusia. Lebih lanjut, dalam jamuan makan bersama-sama, perilaku persetujuan, kesepahaman dan kegembiraan lebih dominan, sehingga membawa dampak postif ketimbang perilaku yang antagonis (Spence, 201: 1-16).

Sudah sejak lama, diplomasi kuliner dipraktikan oleh masyarakat Yunani kuno (Chapple-Sokol, 2013: 161-183), dan mungkin jauh sebelum ditemukannya terminologi gastro diplomasi yang baru muncul di awal era milenial (Economist, 2002). Sementara itu, akan berbeda narasinya jika yang dibicarakan adalah diplomasi makanan (food diplomacy).
Rockower (2012) dan Chapple-Sokol (2013) memiliki paradigma yang sepaham untuk yang satu ini, yang mana diplomasi makanan (food diplomacy) adalah bentuk bantuan makanan dari negara yang satu ke negara yang lain untuk mengurangi persoalan kekurangan pangan atau gizi buruk. Tidak hanya itu saja, tapi bantuan semacam ini juga diperlukan jika suatu negara yang umumnya negara miskin atau kurang berkembang mengalami bencana alam, seperti banjir, kebakaran hutan, gempa bumi, kekeringan, dan lain sebagainya.

\begin{tabular}{ll}
\hline \multirow{2}{*}{$\begin{array}{ll}\text { Dastro } \\
\text { Diplomasi }\end{array}$} & Aktor: Negara/ non-negara \\
\cline { 2 - 2 } & Target: masyarakat mancanegara/ publik \\
\hline Objektif: Mempengaruhi opini publik, membangun citra positif \\
\hline Kiplomasi & Aktor: Negara \\
\cline { 2 - 2 } Kuliner & Target: Pejabat tinggi negara \\
\cline { 2 - 2 } & Objektif: memperkuat hubungan bilateral/mempengaruhi keputusan dalam negosiasi \\
\hline Diplomasi & Aktor: Negara/ non-negara \\
\cline { 2 - 2 } Makanan & Target: Negara berkembang/negara miskin \\
\cline { 2 - 2 } & Objektif: Ruang lingkupnya Humanisme \\
\cline { 2 - 2 }
\end{tabular}

Diagram 2. Dikotomi antar Konsep

\section{Aktivitas Gastro Diplomasi dan Nation}

Branding

Gastro diplomasi merupakan pendekatan holistik yang membutuhkan sponsor negara dalam menjalankan aktivitasnya. Namun demikian, pada era neodiplomasi, impresi terhadap kemajuan teknologi telah mengubah peranan negara yang awalnya adalah aktor utama dalam setiap kegiatan diplomasi menjadi "pengantar pesan" dan berurusan dengan formalitas belaka (Finn, 2003, hal. 15-20). Aktor negara tidak sebegitu krusialnya seperti dulu, karena negara harus giat mengelola soft power dibandingkan hard power. Argumentasinya adalah, dalam abad informasi, kekuatan politik lebih merujuk kepada siapa yang lebih berpengaruh pada opini publik daripada besarnya kekuatan 
militer (Buckle, 2012).

Republik Korea merupakan salah satu dari banyak negara yang melakukan gastro diplomasi. Sudah banyak tulisan yang menyinggung diplomasi melalui gastronomi Republik Korea yang menyatakan strategi yang digunakan negara tersebut masif serta komprehensif. Menyebut Republik Korea tidak mungkin dilepaskan dari pengaruh Halyu (gelombang Korea) di berbagai benua, khususnya Asia (Jang \& Paik, 2012: 196-202). Dalam bidang gastronomi, Republik Korea memiliki resep tersendiri dalam memperkenalkan filosofi dan identitas mereka melalui program Hansik: Korean Cuisine to the World, yang bermula dari agresivitas mantan Presiden Lee Myung-Bak untuk branding seluruh reka cipta Republik Korea, termasuk gastronomi. Hal itu membuat publik mengetahui bahwa kimchi, bulgogi dan gimbab merupakan hasil konstruksi kebudayaan Korea, bukan Jepang atau Tiongkok (Pham, 2013, hal. 1-22). Gastro diplomasi Republik Korea langsung dikelola oleh Korean Food Foundation (KFF) yang sudah berganti nama menjadi Korean Food Promotion Institute (KFPI) yang dibentuk oleh pemerintah

(KoreanFoodPromotionInstitute, 2017). Tujuan dari dibentuknya institusi ini, menurut Pham (2013), adalah untuk urusan Koreas's Brand Image yang berkaitan erat dengan memprominenkan identitas bangsa Korea.
Selain Republik Korea, Peru adalah satu -satunya negara Amerika Latin yang melakukan praktik gastro diplomasi. Pemerintah Peru melalui Kementrian Kebudayaan dan Hubungan Luar Negeri berkolaborasi dengan Komunitas Gastronomi Peru bekerja sama untuk memperkenalkan kuliner tradisional (Wilson, 2013, hal. 13-20). Sociedad Peruana de Gastronomia merupakan komunitas yang mendapatkan legitimasi dari pemerintah Peru untuk menjadi lembaga nonpemerintah yang berperan lebih dalam urusan people to people contact dan memiliki intensi untuk mempromosikan gastronomi sebagai bagian dari warisan budaya masyarakat Peru (APEGA, 2007). Bahkan seorang Diplomat memiliki misi khusus untuk memperkenalkan gastronomi di tempat mereka ditugaskan. Masih banyak negara-negara yang diyakini melakukan praktik gastro diplomasi, seperti Malaysia, Thailand dan Taiwan (Rockower, 2012: 1-12). Kementrian Luar Negeri Indonesia secara implisit mulai mengakui pentingnya gastro diplomasi sebagai penjuru lokomotif ekonomi Indonesia (Diplomasi, 2017). Namun, pemerintah Indonesia masih gagal dalam memahami konsep gastro diplomasi yang rupanya memiliki potensi besar untuk meningkatkan citra negara.

Dari aktivitas diplomasi yang ada, penulis menilai bahwa hasil akhir dari gastro 
diplomasi adalah nation branding di ranah internasional, semisal Republik Korea, Peru, Malaysia, Thailand, Taiwan atau Jepang, sekalipun memiliki motif yang yang serupa, yakni ingin membangun citra positif. Nation branding seringkali diasosiasikan sebagai suatu tindakan untuk mendesain citra yang positif suatu negara melalui pemasaran komunikasi (Anholt, 2013, hal. 6-12). Nation branding tidak bisa lepas dari gastro diplomasi, karena menurut Zhang (2015) banyak negara yang ingin mempopulerkan warisan budaya makanannya. Penelitian yang dilakukan oleh Nirwandy dan Awang (2014), menyatakan gastro diplomasi meningkatkan citra negara, sehingga publik semakin mengenal negara tersebut, sehingga publik akan mengetahui dan tidak akan tertukar lagi berasal dari mana sushi dan sashimi.

Gastro diplomasi juga sering diafiliasikan dengan pariwisata. Ketika berlibur ke Bali, wisatawan juga memikirkan ayam betutu sebagai opsi untuk memahami masyarakat Bali. Artinya, gastro diplomasi memiliki kaitan dengan nation branding dan pariwisata. Oleh sebab itu, dalam tulisannya, Anholt (2013) mengklaim bahwa Republik Korea memiliki strategi yang benar-benar holistik dan memahami konsep brand negara versi Anholt. Pemerintah Republik Korea berhasil mengkomunikasikan brand negara ke berbagai penjuru negara dengan baik, yakni dengan mempaketkan seluruh sumber-sumber yang dimiliki melalui halyu atau gelombang Korea.

\section{Penutup}

Gastro diplomasi sudah menjadi salah satu instrumen unggul bagi banyak negara, khusunya middle powers. Konsep ini merupakan contoh konkret dari soft power, karena menggunakan sumber-sumber yang pendekatannya bukan untuk berperang. Gastro diplomasi mulai dikenal di awal abad milenial, yang kemudian terus berkembang aktivitasnya untuk menciptakan suasana positif bagi negara yang melakukan aktivitas ini. Gastro diplomasi adalah bagian dari diplomasi kebudayaan, sedangkan diplomasi kebudayaan, dinilai merupakan sub dari diplomasi publik. Diplomasi yang menggunakan kuliner, ternyata memiliki sejumlah konsep yang saling bersinggungan satu sama lainnya. Akan tetapi, gastro diplomasi, merupakan pendekatan yang berbeda dengan diplomasi kuliner apalagi diplomasi makanan yang tujuannya adalah membantu negara lain dalam mengatasi masalah kekurangan gizi. Gastro diplomasi merupakan wacana kontemporer dalam disiplin ilmu Hubungan Internasional yang menggunakan unsur kuliner sebagai instrumen komunikasinya. 


\section{Daftar Pustaka}

Anholt, S. (2013). Beyond the Nation Brand: The Role of Image and Identity in International Relations. Exchange: The Journal of Public Diplomacy, 2(1), 6-12.

APEGA. (2007). What is Apega. Retrieved from Sociedad Peruana de Gastronomia: http:// www.apega.pe/nosotros/que-es-apega

Buckle, A. E. (2012). The New Diplomacy: Devising a Relational Model of Public Diplomacy. Pursuit-The Journal of Undergraduate Research at the University of Tennessee, 3(2), 147.

Chapple-Sokol, S. (2013). Culinary Diplomacy: Breaking Bread to Win Hearts and Minds. The Hague Journal of Diplomacy, 161-183.

Cull, N. J. (2006, April 18). Public Diplomacy Before Gullion: The Evolution of a Phrase. Retrieved from USC Center on Public Diplomacy: https://uscpublicdiplomacy.org/blog/ public-diplomacy-gullion-evolution-phrase

Cull, N. J. (2009). Public Diplomacy: Lessons from the Past. Los Angeles : Figueroa Press.

Cummings, M. C. (2003). Cultural Diplomacy and the United States Government: A Survey. Washington DC.: Center for Arts and Culture.

Tabloid Diplomasi. (2017, May 15). Kemenlu dan IGA Intensifkan Promosi Makanan Indonesia. Jakarta, DKI Jakarta, Indonesia: Direktorat Diplomasi Publik.

Economist, T. (2002, February 21). Food as Ambassador Thailand's Gastro Diplomacy. Retrieved from www.economist.com/node/999687

Finn, H. K. (2003). The Case for Cultural Diplomacy: Engaging Foreign Audience. Foreign Affairs, 82(6), 15-20.

Gregory, B. (2008). Public Diplomacy: Sunrise of an Academic Field. The Annals of the American Academy, 616, 274-290.

Jang, G., \& Paik, W. K. (2012). Korean Wave as a Tool for Korea's New Cultural Diplomacy. Scientific Research, 2(3), 196-202.

Ketaren, I. (2016). Gastronomi Upaboga Indonesia. Jakarta: Indonesian Gastronomy Association.

KoreanFoodPromotionInstitute. (2017). The Taste of Korea: Hansik. Retrieved from https:// www.hansik.org/en/article.do?cmd=html\&menu=PEN6010100\&lang=en

Leonard, M. (2002). Diplomacy by Other Means. Foreign Policy.

Leonard, M. (2002). Public Diplomacy. London: The Foreign Policy Centre.

Mark, S. (2003). Discussion Paper: A Greater Role of Cultural Diplomacy. Netherlands Institute of International Relations, 1-44.

Martosko, D. (2017, November 7). Daily Mail Online. Retrieved from http:// www.dailymail.co.uk/news/article-5058273/South-Korean-president-hosts-Trump-lavishstate-dinner.html

Mellisen, J. (2005). The New Public Diplomacy: Between Theory and Practice. In J. Mellisen, \& J. Mellisen (Ed.), The New Public Diplomacy: Soft Power in International Relations (pp. 3 -23). New York: Palgrave Macmillan. 
Nirwandy, N., \& Awang, A. A. (2014). Conceptualizing Public Diplomacy Social Convention Culinary: Engaging Gastro Diplomacy Warfare for Economic Branding. Procedia-Social and Behaviroal Sciences , 325-332.

Nye, J. (2004). Soft Power and AMerican Foreign Policy . Political Science Quarterly, 255-270.

Pham, M. J. (2013). Food as Communication: A Case study of South Korea's Gastrodiplomacy. Journal of International Service, 1-22.

Purwasito, A. (2016). Gastro Diplomasi Sebagai Penjuru Diplomasi Ekonomi Indonesia. Surakarta: BPPK Kemlu-Prodi HI Universitas Sebelas Maret.

Rockower, P. S. (2012). Recipes for Gastrodiplomacy. Macmillan Publishers, 1-12.

Schneider, C. (2005). Culture Communicates: US Diplomacy that Works. In J. Mellisen, The New Public Diplomacy: Soft Power in International Relations (pp. 147-168). London: Palgrave Macmillan.

Schneider, C. (2006). Cultural Diplomacy: Hard to Define but You'd Know if You Know it. Brown Journal of World Affairs, XIII(1), 191-203.

Spence, C. (2016). Gastrodiplomacy: Assesing the Role of Food in Decision-Making. Biomed Central, 1-16.

Tettner, S., \& Kalyoncu, B. (2016). Gastrodiplomacy 2.0: Culinary Tourism Beyond Nationalism. Journal of Tourism Research, 47-55.

ThaiFoodtotheWorld. (2005, July 21). The Policy of the Government on the Thai Cuisine to the World. Retrieved from www.thaifoodtoworld.com/home/governmentpol.php

Thies, C., \& Pecquet, G. (2010). The Shaping of a Future President's Economic Thought. The Independence Review, 15(2), 257-277.

Wilson, R. (2013). Cocina Peruana Para El Mundo: Gastrodiplomacy, the Culinary Nation Brand, and the Context of National Cuisine in Peru. Exchange: The Journal of Public Diplomacy, $13-20$.

Zhang, J. (2015). The Foods of the Worlds: Mapping and Comparing Contemporary Gastrodiplomacy Campaigns. International Journal of Communication, 568-591. 